\title{
Construindo Maquetes - Uma Estratégia Didática Interdisciplinar no Eixo Geometrias: Espaço e Forma
}

\author{
Carla Denize Ott Felcher ${ }^{1}$, Lisete Funari Dias² ${ }^{2}$ Crisna Daniela Krause Bierhalz³
}

1 Professora da UAB/UFPel no Curso de Licenciatura em Matemática - Pelotas/RS. Brasil. carlafelcher@gmail.com

2 Doutoranda na Universidade Federal do Rio Grande do Sul, Docente na Universidade Federal do PampaCampus Dom Pedrito/ RS. Brasil. lisetefunaridias@gmail.com

3 Professora Doutora da Universidade Federal do Pampa - Campus Dom Pedrito/RS. Brasil. crisnakrause@gmail.com

\section{Resumo}

Este trabalho tem por objetivo socializar e discutir os resultados de aprendizagem relacionados a uma estratégia didática: a construção de maquetes virtuais e físicas propostas no Curso de Licenciatura em Matemática a Distância (CLMD), da Universidade Federal de Pelotas, Projeto Universidade Aberta do Brasil (UAB3/ PARFOR), no segundo semestre de 2012. O currículo, organizado por Eixos Temáticos, tem seu planejamento com enfoque interdisciplinar. O foco deste trabalho é o Eixo Geometrias: Espaço e Forma. A base teórica deste trabalho utiliza a teoria da interdisciplinaridade, apoiada em Almeida \& Passini (2002), Oliveira \& Velasco (2007), Lenoir (2012), Trindade (2013) e Mello (1998). A pesquisa caracteriza-se metodologicamente como um estudo de caso, com análise qualitativa sobre dados coletados no Ambiente Virtual de Aprendizagem (Moodle), tais como os blogs dos polos e os registros nos portfólios virtuais, um dos instrumentos de avaliação propostos. Utiliza-se, para esta análise, a metodologia da Análise Documental (Ludke \& Andre, 1986). Destaca-se, como resultado, que a estratégia didática ultrapassou os objetivos estabelecidos pelos professores, pois além dos conceitos geométricos, de física e de educação ambiental, a construção da maquete envolveu conhecimentos históricos e culturais da região em um trabalho colaborativo. Foi uma experiência significativa, segundo os registros dos próprios alunos pois, além de servir para construção da sua aprendizagem, a maquete foi utilizada pelos alunos que já atuam como professores nas suas práticas pedagógicas.

Palavras-Chave: Educação a distância; Maquete; Interdisciplinaridade; Aprendizagem significativa. 


\title{
Building Maquetes: Interdisciplinary Teaching Strategy in Axle and Shape of Space Geometry UFPel
}

\begin{abstract}
This paper aims at socializing and discussing the learning outcomes related to a teaching strategy: the construction of virtual and physical scale models proposed in the Mathematics Degree Distance Course (CLMD), from Universidade Federal de Pelotas, Project Open University in Brazil (UAB3/PARFOR) in the second half of 2012. The curriculum is organized by Thematic Groups, with interdisciplinary focus. The focus of this work is the Axis Geometries: Space and Shape. The theoretical basis of this work uses the interdisciplinary theory, supported by Almeida \& Passini (2002), Oliveira \& Velasco (2007), Lenoir (2012), Trindade (2013) and Mello (1998). The research is conducted methodologically as a case-study with a qualitative analysis of data collected in the Virtual Learning Environment (Moodle), such as learning center's blogs and records from the virtual portfolios, which are some of the proposed assessment tools. For this analysis, it is used the Document Analysis (LUDKE \& ANDRE, 1986) methodology. It is important to emphasize that, as a result, the teaching strategy exceeded the objectives set by teachers, because, besides the geometrical concepts, physical and environmental education, the process of building a scale model has involved the place's historical and cultural knowledge in a collaborative work. It was a meaningful experience, according to the students because, besides serving for the construction of their learning, the scale model was used by students who are working already as teachers in their pedagogical practice.
\end{abstract}

Keywords: Distance education; Mockup; Interdisciplinary; Meaningful learning. 


\section{Introdução}

Este trabalho tem por objetivo socializar e discutir uma estratégia didática interdisciplinar desenvolvida a partir da construção de maquetes virtuais e físicas no Eixo Temático Geometrias: Espaço e Forma, no Curso de Licenciatura em Matemática a Distância (CLMD) da Universidade Federal de Pelotas, Projeto Universidade Aberta do Brasil (UAB3/PARFOR), no segundo semestre de 2012, para 22 polos e um total de 578 alunos.

O currículo do curso está organizado por eixos temáticos distribuídos em oito semestres de acordo com a legislação sobre os currículos das licenciaturas (Brasil, 2002). Esse currículo foi constituído a partir da reestruturação do Projeto Pedagógico do Curso - PPC, organizado através de um currículo não sequencial, cujos eixos temáticos estão voltados para a formação inicial do professor de Matemática, indo além do domínio dos conteúdos matemáticos. Assim, a formação desse professor, até então fragmentada, baseada em conhecimentos específicos e dissociados, é proposta de maneira não linear a partir da interconexão de quatro conhecimentos, chamados de conhecimentos necessários para a formação do professor de Matemática, apresentados na Figura 1.

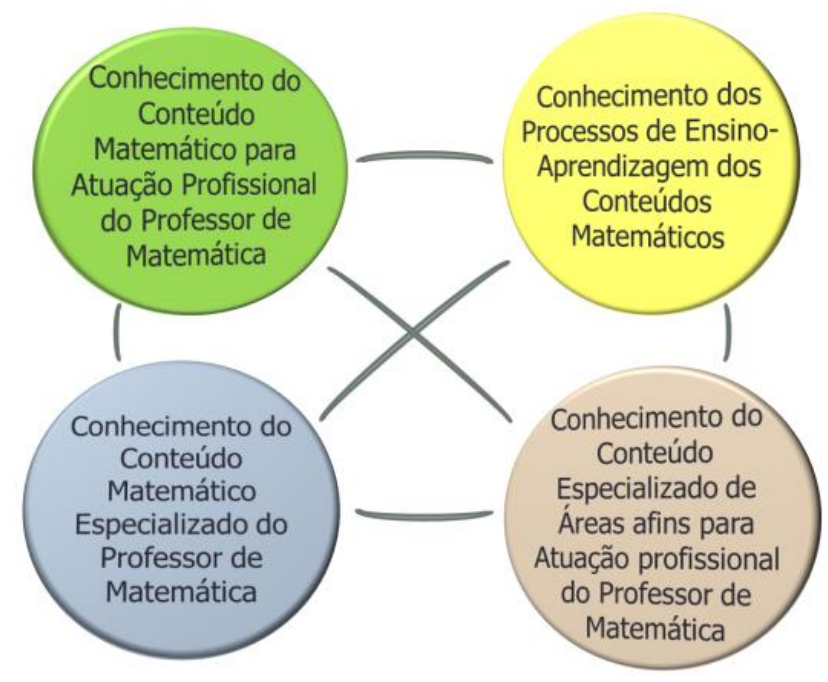

Figura 1: Conhecimentos necessários para a formação do professor de Matemática. 
Esses conhecimentos encontram significação com o estudo de conceitos matemáticos, que foram agrupados nos oito eixos temáticos apresentados na Figura 2. Tais eixos não possuem uma sequência predefinida de execução, além disso, nenhum é pré-requisito de outro e cada um contém todos os conceitos necessários para a sua integralização.

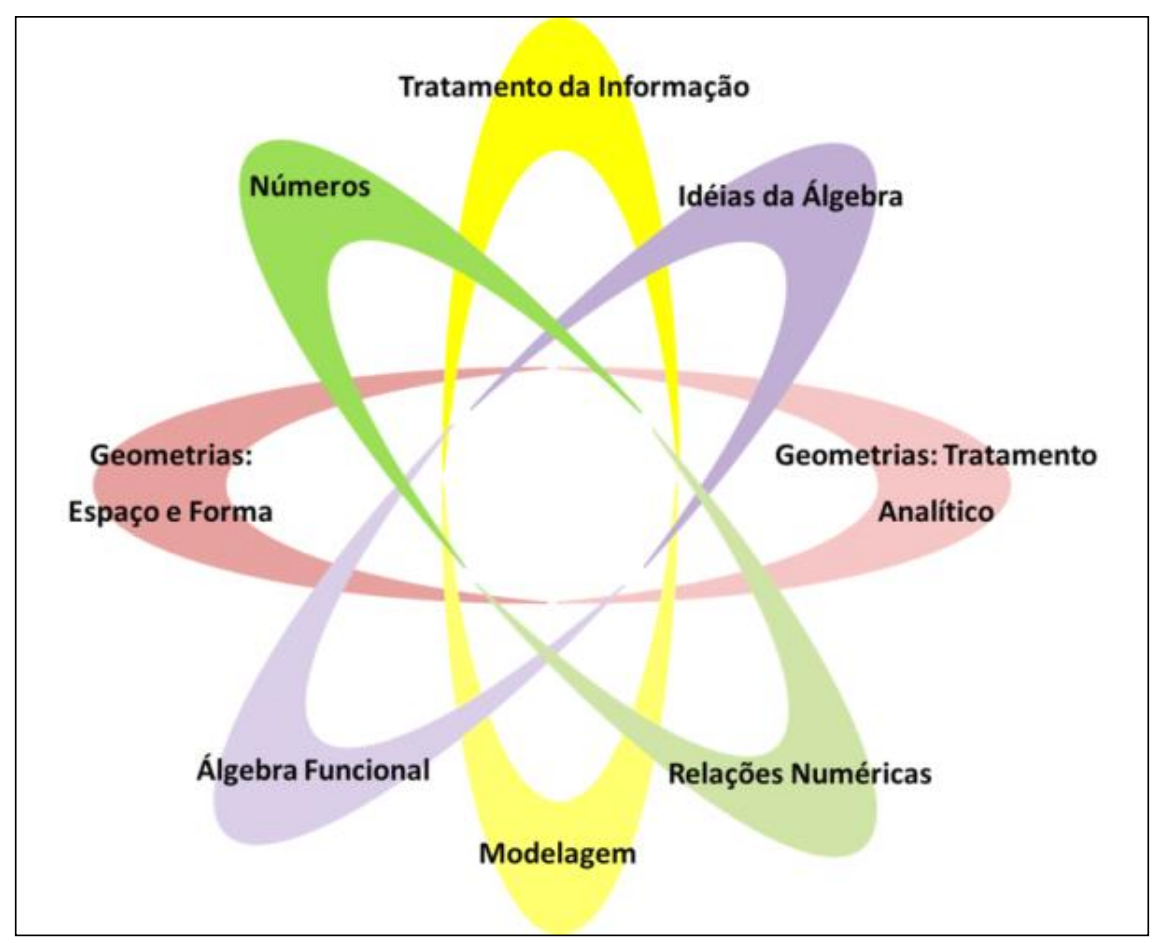

Figura 2: Eixos temáticos do Currículo do CLMD.

Fonte: CLMD.

Cada eixo é sempre iniciado por uma situação-problema instigadora, na qual o aluno é o ator principal de seu próprio processo de aprendizagem, agindo sempre em colaboração e com a participação de professores, tutores e colegas. No caso do Eixo Geometrias: Espaço e Forma, foco deste trabalho, a situação problema consistiu em fotografias de pontos turísticos ou prédios históricos das cidades dos polos dos alunos, induzindo-os a fazer uma reflexão sobre as relações dos conceitos matemáticos com o momento sociopolítico-histórico nos quais se originaram e se estabeleceram, respeitando as diferentes culturas de cada região. 
Todas as estratégias pedagógicas planejadas tiveram o objetivo de estimular o raciocínio hipotético-dedutivo e a visão espacial próprios do pensar matemático. No entanto, este artigo foca-se na estratégia pedagógica, resultante da atividade das fotografias, intitulada confecção de maquetes física e virtual, sendo esta última construída com o software SketchUp. O SketchUp é um software livre, extremamente versátil e fácil de usar, que oferece um conjunto de ferramentas para a criação, modificação e modelagem em 3D. O SketchUp pode ser usado por qualquer atividade profissional que necessite desenvolver rascunhos de produtos tridimensionais.

Durante a execução do Eixo, as estratégias são propostas semanalmente e têm o apoio das mídias digitais desenvolvidas no Ambiente Virtual de Aprendizagem Moodle. Também são oferecidas atividades presenciais semanais não obrigatórias, nas quais o grupo de estudantes de cada polo pode se reunir a fim de realizar uma experimentação com os conteúdos propostos de forma social e colaborativa. Cada atividade presencial, além de trabalhar questões conceituais, visa proporcionar integração entre o grupo, tornando o aprendizado mais participativo. Além dessas propostas, também são oferecidas avaliações presenciais, constituindo atividades presenciais obrigatórias na forma da lei.

Durante 19 semanas, foram organizados materiais, recursos, avaliações e atividades para interconexão dos quatro conhecimentos, apresentados na Figura 1, em relação ao tema Geometria. Uma dessas propostas será exposta a seguir.

\section{A construção de Maquetes: uma estratégia pedagógica interdisciplinar}

No quadro a seguir (Quadro 1), apresentamos uma visão conceitual geral a respeito do Eixo Geometrias: Espaço e Forma, com o objetivo de demonstrar as diversas possibilidades de construir conceitos da geometria por meio da atividade das maquetes. 
Quadro 1: Conteúdo Programático do Eixo Geometrias: Espaço e Forma.

\begin{tabular}{|c|c|c|c|}
\hline $\begin{array}{l}\text { Conhecimento do } \\
\text { Conteúdo para } \\
\text { Atuação Profissional } \\
\text { do Professor de } \\
\text { Matemática } \\
\text { (Educação Básica) }\end{array}$ & $\begin{array}{l}\text { Conhecimento do } \\
\text { Conteúdo Matemático } \\
\text { Especializado do } \\
\text { Professor de } \\
\text { Matemática (Educação } \\
\text { Superior) }\end{array}$ & $\begin{array}{l}\text { Conhecimento dos } \\
\text { Processos de Ensino- } \\
\text { Aprendizagem dos } \\
\text { Conteúdos } \\
\text { Matemáticos }\end{array}$ & $\begin{array}{l}\text { Conhecimento do } \\
\text { Conteúdo } \\
\text { Especializado de } \\
\text { Áreas Afins para } \\
\text { Atuação Profissional }\end{array}$ \\
\hline $\begin{array}{c}\text { Figuras } \\
\text { bidimensionais e } \\
\text { tridimensionais: } \\
\text { Distinção } \\
\text { Classificação, } \\
\text { representação. } \\
\text { Transformações } \\
\text { geométricas. Noções } \\
\text { de topologia. Posições } \\
\text { relativas entre entes } \\
\text { geométricos. } \\
\text { Medidas. }\end{array}$ & $\begin{array}{c}\text { Desenho Geométrico: } \\
\text { Construções } \\
\text { fundamentais, pontos } \\
\text { singulares no triângulo, } \\
\text { lugar geométrico. } \\
\text { Desenvolvimentos da } \\
\text { visualização espacial: } \\
\text { perspectivas, vistas: } \\
\text { Raciocínio hipotético- } \\
\text { dedutivo da Geometria } \\
\text { Espacial e Plana } \\
\text { Euclidiana. Geometria } \\
\text { de posição. Geometria } \\
\text { métrica. Topologia: } \\
\text { Conceitos básicos, } \\
\text { transformações e } \\
\text { estruturas. Lógica } \\
\text { Matemática: } \\
\text { Argumentações e } \\
\text { Provas. }\end{array}$ & $\begin{array}{c}\text { Psicologia da } \\
\text { Educação } \\
\text { Matemática: Teorias } \\
\text { de Aprendizagem, } \\
\text { análise de erros e de } \\
\text { dificuldades de } \\
\text { aprendizagem para } \\
\text { o conteúdo } \\
\text { específico do eixo. } \\
\text { Tendências em } \\
\text { Educação } \\
\text { Matemática. } \\
\text { Processos avaliativos } \\
\text { matemáticos: tipos e } \\
\text { instrumentos de } \\
\text { avaliação. História } \\
\text { do conteúdo } \\
\text { específico do eixo } \\
\text { em diferentes povos } \\
\text { e culturas. }\end{array}$ & $\begin{array}{c}\text { Organização e } \\
\text { políticas públicas de } \\
\text { educação (Projeto } \\
\text { Político Pedagógico, } \\
\text { Plano de ensino e } \\
\text { planos de aula), LDB, } \\
\text { PCNs, Educação } \\
\text { Especial. Língua } \\
\text { Brasileira de Sinais } \\
\text { com foco no conteúdo } \\
\text { específico. Leitura } \\
\text { específica, } \\
\text { interpretação e } \\
\text { argumentação crítica. } \\
\text { Estudo da óptica } \\
\text { geométrica. }\end{array}$ \\
\hline
\end{tabular}

Fonte: CLMD.

Para desenvolver as disciplinas do Eixo Geometrias: Espaço e Forma, apresentadas no Quadro 1, e os respectivos conceitos, o planejamento do Eixo Geometrias: Espaço e Forma partiu da perspectiva de interdisciplinaridade, que envolveu o grupo de nove professores (seis especializados em áreas diversificadas da 
Matemática, um de Física, um da Psicologia da Educação e um da Pedagogia), tendo, como referência, a ementa que faz parte do Projeto Pedagógico e um cronograma de atividades. Segundo Lenoir (2012), "a interdisciplinaridade pressupõe a existência de ao menos duas disciplinas como referência e a presença de uma ação recíproca" (Lenoir, 2012, p.143).

Nessa perspectiva, é construído o material didático, denominado de material base. Este é produzido pelos professores e apresentado aos alunos, semanalmente, de forma que os conteúdos tenham relação e dialoguem entre si. Esse diálogo é mediado, nos textos, por uma professora virtual, conforme se percebe na Figura 3, conectando assim, as ideias de todos os conteúdos envolvidos.

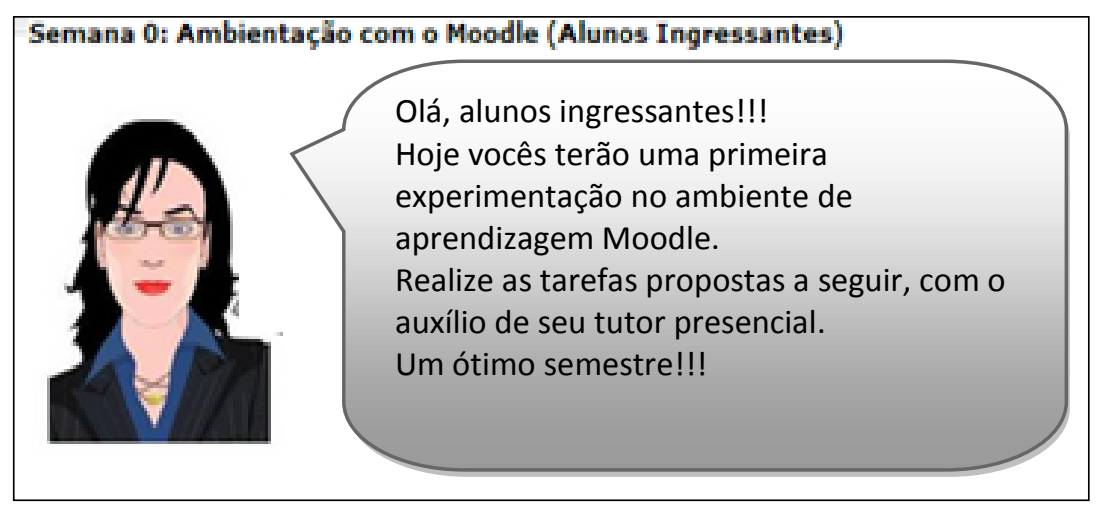

Figura 3: A professora virtual.

Fonte: Material Base do Eixo Geometrias: Espaço e Forma.

A construção de maquetes, como estratégia interdisciplinar, vem ao encontro do conceito de interdisciplinaridade, apresentado por Trindade (2013, p. 88): "a interdisciplinaridade pressupõe uma desconstrução, uma ruptura com o tradicional e com o cotidiano tarefeiro escolar". Ainda, segundo o mesmo autor, o professor interdisciplinar mantém uma postura flexível percorrendo fronteiras, disposto a realizar trabalhos pautados na interdependência, no compartilhamento, no encontro, no diálogo e nas transformações.

Segundo Almeida \& Passini (2002), a maquete é capaz de representar com fiel aproximação, através das escalas, o espaço em que se vive. A construção de uma maquete permite trabalhar conceitos de diferentes disciplinas, propiciando ao indivíduo 
a ação sobre o objeto, permitindo a construção de conceitos. Nesse sentido, os Parâmetros Curriculares Nacionais de Matemática - PCNs (Brasil, 1998, p. 128) reforçam que "Construir maquetes e descrever o que nelas está sendo representado é também uma atividade muito importante, especialmente no sentido de dar ao professor uma visão do domínio geométrico de seus alunos."

Já para Mello (1998), a construção de um conceito:

[...] fica mais claro quando se considera o fato trivial de que todo conhecimento mantém um diálogo permanente com outros conhecimentos, que pode ser de questionamento, de confirmação, de complementação, de negação, de ampliação, de iluminação de aspectos não distinguidos (Mello, 1998, p. 38).

Nessa perspectiva, no Eixo Geometrias: Espaço e Forma e, principalmente, no trabalho apresentado neste artigo, que se refere à construção de maquetes, parte-se do princípio de que as disciplinas do eixo não podem se isolar e, para isso, é necessário que cada vez mais os professores trabalhem no planejamento colaborativo, percebendo essas aproximações e dando significado ao que ensinam. O contrário disso se confirma no pensamento de Oliveira \& Velasco (2007), quando tratam da ausência ou quase ausência do ensino da geometria, apresentada aridamente, desligada da realidade, não integrada com as outras disciplinas do currículo e até mesmo não integrada com as outras partes da própria Matemática. O fato é que a geometria está em todo o lugar e pode ser facilmente pensada na prática pedagógica de professores como trabalho interdisciplinar. Essa prática interdisciplinar precisa ser estimulada nos cursos de licenciatura, para que os alunos a vivenciem e possam sentir-se seguros para trabalhar com as propostas em suas aulas na Educação Básica.

De acordo com Mello (1998):

A interdisciplinaridade também está envolvida quando os sujeitos que conhecem, ensinam e aprendem, sentem necessidades de procedimentos que, numa única visão disciplinar, podem parecer heterodoxos, mas fazem sentido quando chamados a dar conta de temas complexos.(...) Nesta multiplicidade de interações e negociações recíprocas, a relação entre as disciplinas tradicionais pode ir da simples comunicação de ideias até a integração mútua de conceitos diretores, da epistemologia, da terminologia, da metodologia e dos procedimentos de coleta e análise de dados. Ou pode efetuar-se, mais singelamente, pela constatação de como são diversas as várias formas de conhecer. Pois até mesmo a "interdisciplinaridade singela" é importante para que os alunos aprendam a olhar o mesmo objeto sob perspectivas diferentes. (Mello, 1998, p. 38) 
Este artigo apresenta sua justificativa apoiado na reflexão teórica desenvolvida por Oliveira \& Velasco (2007), pois a diversificação das estratégias pedagógicas no ensino de Matemática também possibilita diversificadas formas de aprendizado. Dessa forma, o aluno ultrapassa o espaço do ensino tradicional, explora, vivencia espaços de troca, tornando-se pesquisador e protagonista de seu processo ensino-aprendizagem.

Nessa perspectiva, apresentamos o planejamento das estratégias didáticas Fotografias e Construção de maquetes.

\section{Metodologia}

\subsection{Os dados e a técnica de análise}

O Eixo Geometrias: Espaço e Forma aconteceu no segundo semestre de 2012 e teve um total de 578 estudantes distribuídos em 22 polos do Rio Grande do Sul.

A escolha das atividades a serem analisadas ocorreu de forma aleatória, considerando, para a coleta de dados, os documentos do Ambiente Virtual de Aprendizagem (Moodle), entre eles: roteiro de avaliações, roteiros de encontros presenciais bem como os blogs dos polos que, embora estejam linkados no Moodle, também podem ser acessados fora dele e cerca de 360 portfólios, um dos instrumentos de avaliação de aprendizagem utilizados no Eixo, os quais somavam $16 \%$ da nota. Quanto à escolha dos portfólios, a preferência foi para os postados no Moodle na $16^{\mathrm{a}}$ semana, pois nesses estavam contidos todos os trabalhos do semestre, com imagens e depoimentos dos alunos, demonstrando todo o processo que levou à construção das maquetes.

O portfólio permitia ao aluno expressar suas aprendizagens e dificuldades no decorrer da semana, tanto por texto, quanto por imagens.

A respeito dos blogs, podemos citar que cada polo construiu o seu e que este, segundo Pinto, Felcher \& Otte (2014), tem como principal objetivo relatar as atividades desenvolvidas nos encontros presenciais, permitindo, assim, que a equipe de planejamento e execução pudesse melhor acompanhar o andamento do eixo em cada polo. 
Trata-se de um estudo de caso, cujo método de análise dos dados utiliza-se da Análise Documental, sendo a discussão de resultados apresentada de forma qualitativa e descritiva. Ludke \& André (1986) apresentam, como vantagem da metodologia Análise Documental, o fato de que os documentos constituem-se uma fonte estável e rica, podendo ser consultados várias vezes.

Para apresentar e discutir os resultados, já que a escolha foi aleatória, procuramos trazer algumas imagens que demonstram todo o processo, desde a atividade da fotografia, do desenho técnico em perspectiva, da elaboração das maquetes virtuais com SketchUp, assim como as maquetes físicas construídas com materiais de sucata e baixo custo.

\subsection{Atividade Maquetes}

A construção de maquetes foi pensada e direcionada, desde o início das atividades do Eixo Temático Geometrias: Espaço e Forma, com os seguintes objetivos: desenhar geometricamente; desenvolver a visualização espacial; desenvolver o raciocínio hipotético-dedutivo da Geometria Plana e Espacial e construir conceitos de Geometria da Posição, métrica e topológica. A primeira atividade (Atividade 1, em Anexo), sobre as fotografias, foi direcionada aos alunos sem que os mesmos soubessem qual seria a continuidade do trabalho. Dessa forma, solicitou-se que cada aluno escolhesse um ponto turístico, prédio histórico, monumento da sua cidade ou da região e fotografasse conforme a seguinte orientação:

Seguindo as orientações da avaliação, o aluno deveria fotografar o prédio escolhido de três ângulos diferentes, sendo que uma das fotografias deveria se assemelhar com a perspectiva isométrica, conceito estudado naquela semana.

Após, o aluno deveria fazer um esboço, em forma de perspectiva isométrica, de uma das fotografias obedecendo às proporções e a escala aproximada. Os conceitos de escala foram introduzidos no material base de forma que o aluno percebesse que uma escala é um método de ordenação que permite a comparação e pode ser utilizada para ampliar ou reduzir, correspondendo a uma relação existente entre as medidas reais e o que é apresentado no papel. Nesse caso, estamos utilizando a escala para reduzir o prédio, monumento ou ponto turístico, tendo por base uma das fotografias. 
A partir da $11^{\text {a }}$ semana, tendo sido explorados todos os conceitos da geometria, da física aplicada, de ilusão de óptica explicada pela psicologia e da educação ambiental, o planejamento considerou que, nos encontros presenciais realizados nos polos, fossem construídas as maquetes. Primeiramente, organizaram-se os grupos de acordo com a primeira avaliação atividade das fotografias. Ou seja, aqueles que fotografaram o mesmo prédio, agora, constituíram um grupo. Geralmente, quando se propõem atividades em grupos, os mesmos se formam por afinidade, pois já trabalharam juntos em outras disciplinas. Essa dinâmica teve por objetivo fazer com que os alunos saíssem da zona de conforto, pois teriam que trabalhar com outros colegas e o critério foi a fotografia inicial.

Os grupos deveriam elaborar, primeiramente, a maquete virtual com o Software SkechUp, software já utilizado no encontro presencial. Através da ferramenta webconferência, foram realizadas oficinas de exploração do Software SketchUp, assim como, a avaliação on-line 4 também consistiu na utilização desse software. A partir daí, elaboraram a maquete física conforme as instruções expressas na Figura 4.

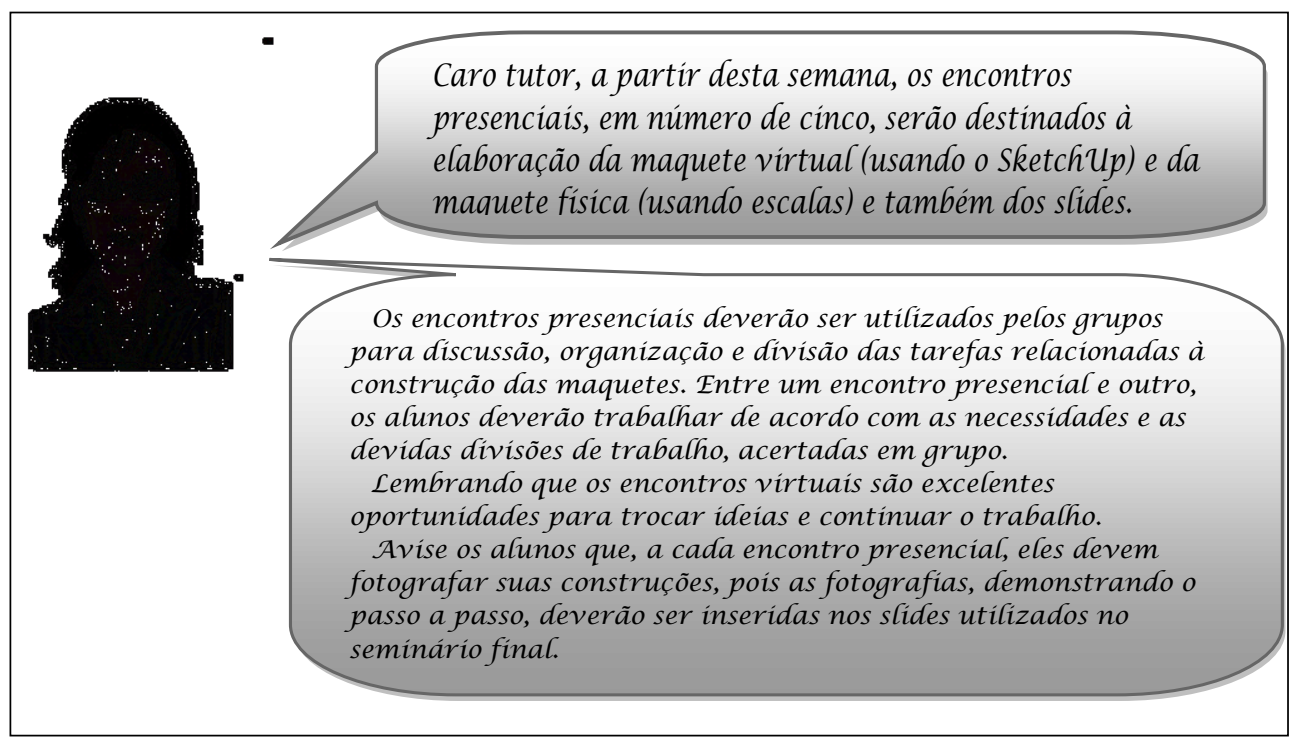

Figura 4: Orientações para construção da maquete virtual e física.

Fonte: Material Base do Eixo Geometrias: Espaço e Forma.

Junto à proposta de construção das maquetes, buscou-se questionar os alunos a respeito dos seus objetivos bem como dos elementos e etapas necessários para a sua 
realização conforme Figura 5. Esses questionamentos não tiveram a intenção de que fossem respondidos e sim que servissem de reflexão no momento da construção da maquete.

\footnotetext{
Construção de Maquetes

Toda maquete tem um objetivo, seja um trabalho acadêmico, seja na arquitetura para exposição de um prédio a venda ou ainda nas artes. Assim, esta é a primeira etapa a ser seguida na construção da maquete. Devo me perguntar: Qual o objetivo da construção da maquete? Ainda pode ser que você tenha uma tarefa de uma disciplina que envolva geometria. Você já imaginou quantos elementos geométricos estarão envolvidos na construção de uma maquete?

Feito isso, a segunda etapa consiste em planejar. Devo me perguntar: O que quero representar? Quais dimensões estão envolvidas no objeto real? E quais dimensões estão envolvidas no espaço disponível? (por exemplo, uma mesa onde será construída a maquete).

A partir daí, definirei uma escala para a construção da maquete. Se o objeto for de dimensões muito maiores, uso uma escala de redução.
}

Figura 5: Questionamentos feitos aos alunos.

Fonte: Material Base do Eixo: Geometrias Espaço e Forma.

Ao final da confecção da maquete física e virtual, os alunos deveriam elaborar um seminário de apresentação das maquetes, assim como apresentarem o produto Maquetes. Essa atividade correspondeu a $30 \%$ do total da nota do aluno. Essa avaliação objetivou buscar elementos da geometria desenvolvidos desde a primeira semana de atividades no eixo.

\subsection{Resultados: A atividade das maquetes em todas as suas fases}

Por meio dos resultados apresentados nos 360 portfólios da $16^{\text {a }}$ semana e blogs dos polos, buscamos elementos que demonstrassem as aprendizagens do Eixo Temático Geometrias: Espaço e Forma, que teve como objetivo desenhar geometricamente; desenvolver a visualização espacial; desenvolver o raciocínio hipotético-dedutivo da Geometria Plana e Espacial e construir conceitos de Geometria da Posição, métrica e topológica. 
A primeira atividade, das fotografias, que envolveu vistas ortogonais e perspectiva isométrica, teve como objetivo principal desenvolver a visão espacial. Como mencionado anteriormente, cada aluno escolheu e fotografou um prédio histórico em três ângulos diferentes. Nesse sentido, a Figura 6 apresenta fotografias de diferentes ângulos do Museu Comunitário Casa Schmitt, construído na primeira metade do século XIX, localizado na cidade de Novo Hamburgo no Rio Grande do Sul.

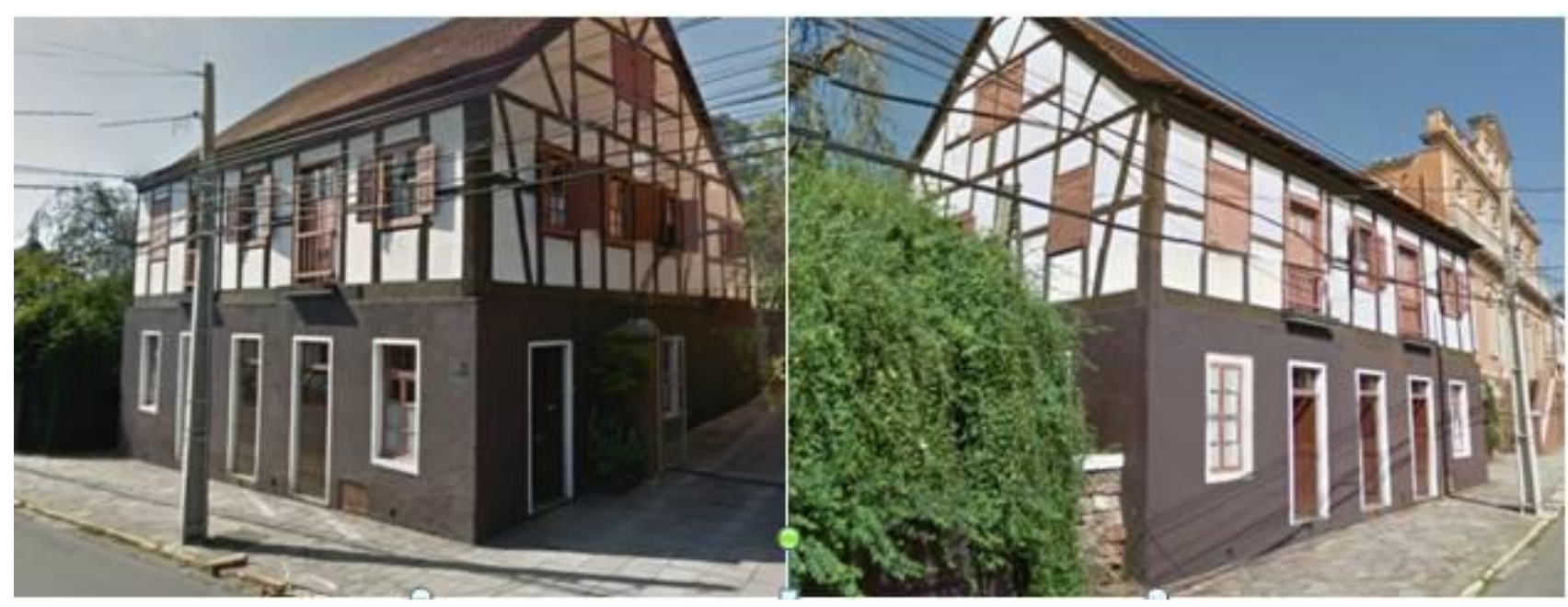

Figura 6: Fotografias de diferentes ângulos.

Fonte: Os portfólios virtuais do Eixo.

Ainda, na mesma atividade, foi solicitado que o aluno fizesse o esboço da fotografia em perspectiva isométrica, o que é apresentado na Figura 7.

Além do planejamento e execução de todas as atividades do Eixo, a atividade das maquetes virtuais necessitou que os professores oferecessem oficinas realizadas nos encontros presenciais através da ferramenta webconferência. Nessas, os alunos puderam explorar o Software SketchUp. A Figura 8 apresenta o tetraedro ABCD, construído pelo aluno, que foi solicitado na avaliação 4 . Ele representou I como um ponto do segmento $A B$ e J como um ponto do segmento AC. 


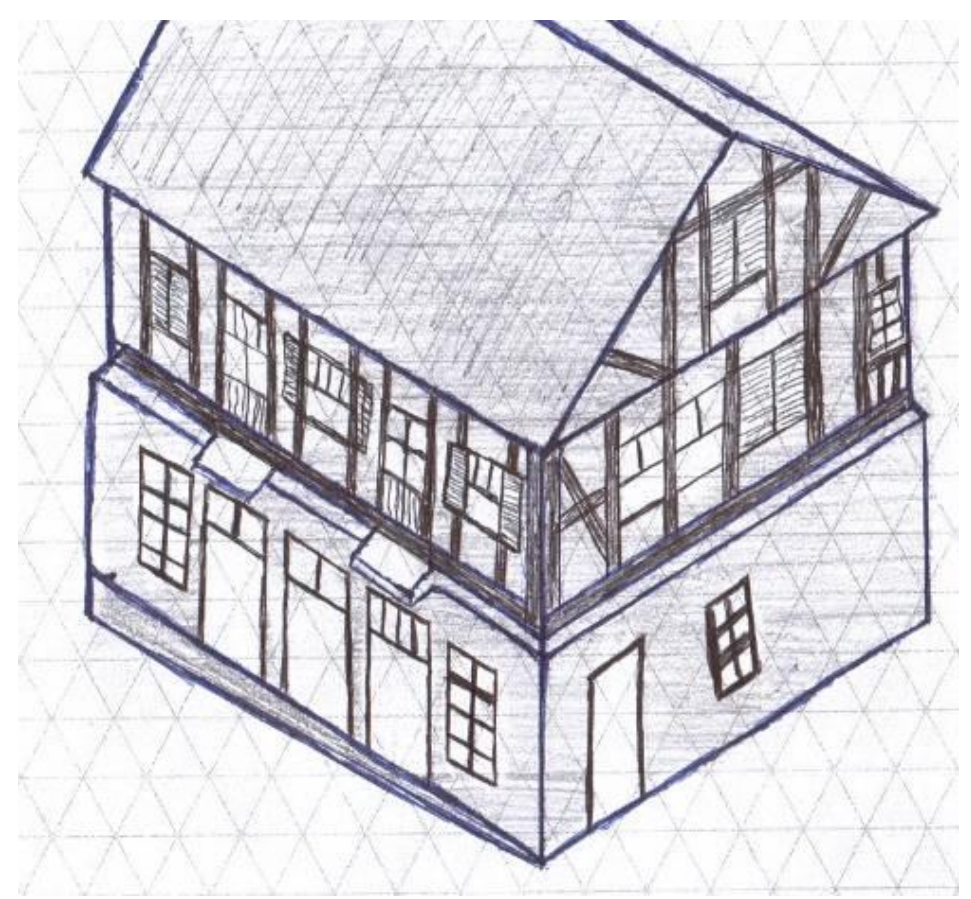

Figura 7: Esboço da fotografia.

Fonte: Os portfólios virtuais do Eixo.

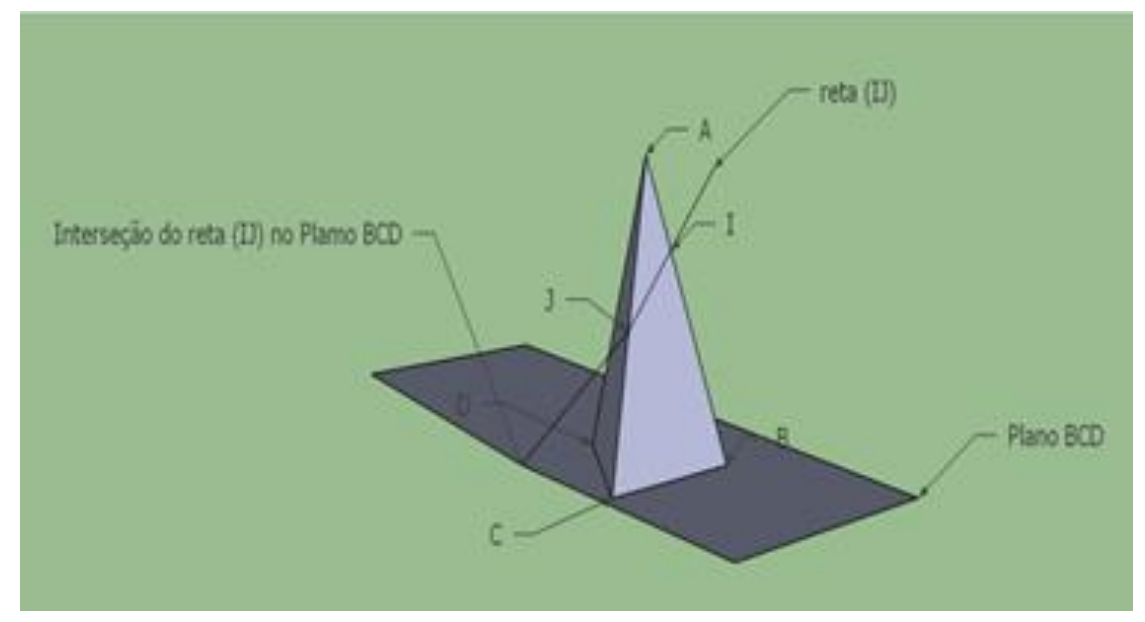

Figura 8: Tetraedro construído no SketchUp. Fonte: avaliação 4 Eixo.

Até esse momento, os alunos não sabiam que teriam as atividades das maquetes. Somente após a $11^{a}$ semana, receberam as instruções e, nessas, estavam 
contidas a solicitação da maquete virtual, da física e apresentação, em seminários, de todos os passos e todas as aplicações dos conceitos geométricos ensinados no Eixo.

Como exemplo de resultado, a Figura 9 apresenta uma maquete virtual construída no Software SketchUp e, ao lado, a Figura 10, a maquete física correspondente.

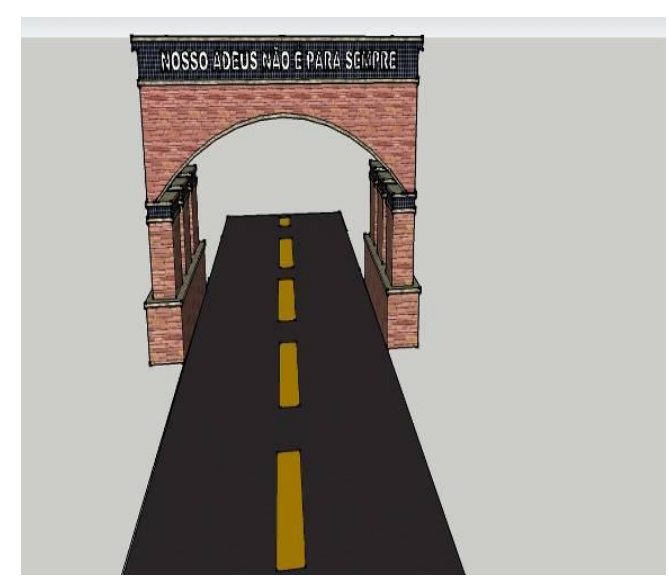

Figura 9: Maquete virtual.

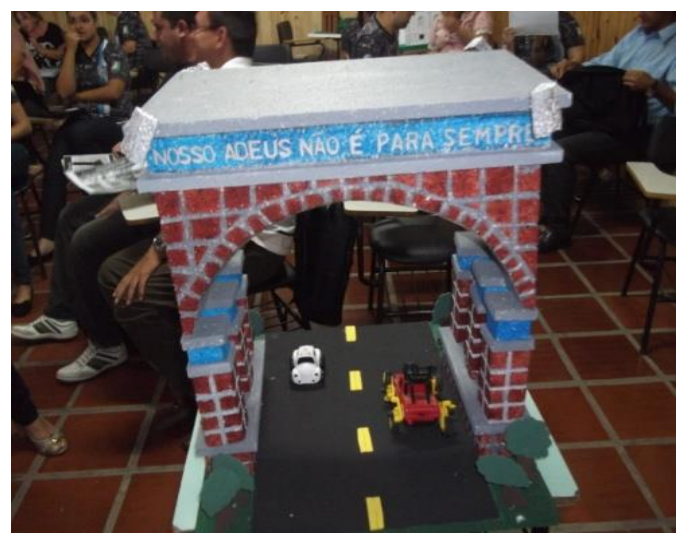

Figura 10: Maquete física.

Fonte: Os portfólios virtuais do Eixo.

É importante salientar que as maquetes físicas foram orientadas no sentido de explorar os princípios da Educação Ambiental, mais especificamente a importância dos $5 R$, que contemplam Repensar, Recusar, Reduzir, Reciclar e Reutilizar. Os alunos fizeram levantamento de dados em relação à coleta de resíduos nos municípios, incentivos das prefeituras à coleta seletiva e aplicaram os princípios da reciclagem e reutilização, quando foram desafiados a construírem as maquetes físicas, com materiais de sucata. Todas as maquetes físicas foram construídas após a construção da maquete virtual. A Figura 11 apresenta uma maquete desenvolvida a partir da reutilização de materiais.

Na Figura 12, além do print de telas da construção da maquete virtual e da maquete física, é possível perceber os materiais recicláveis que foram utilizados na construção da maquete, tais como caixas de produtos de higiene, palitos, isopor, rolos, entre outros. 


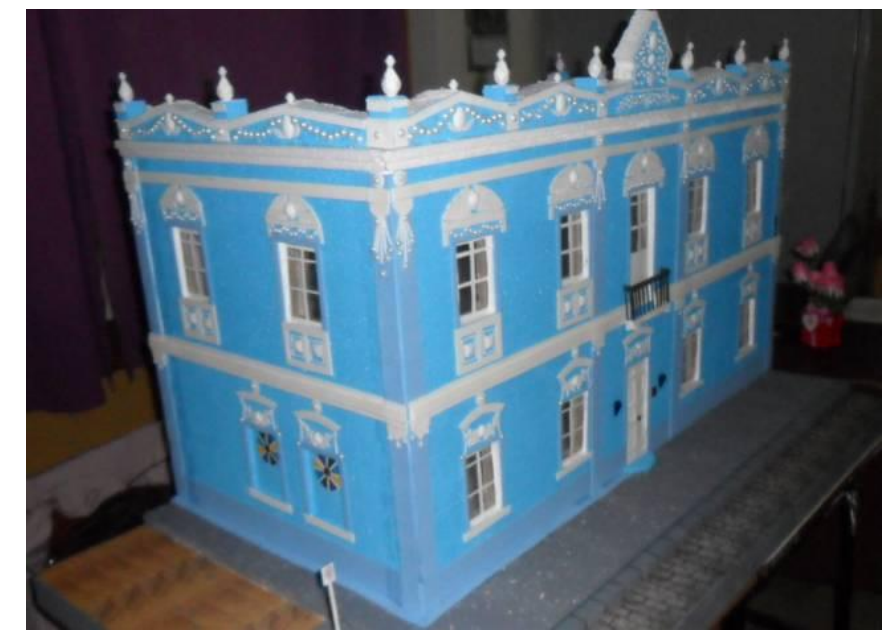

Figura 11: Maquete física construída com materiais de sucata.

Fonte: Os portfólios virtuais do Eixo.
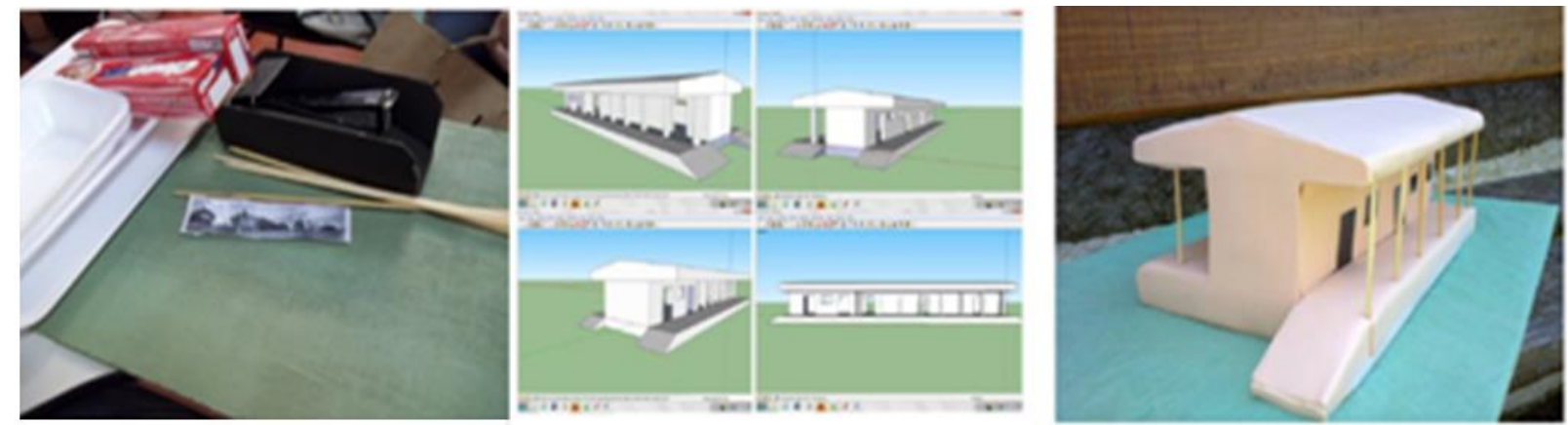

Figura 12: Materiais de sucata, print da tela do software e maquete física.

Fonte: Os portfólios virtuais do Eixo.

Ainda, na Figura 12, é possível acompanhar a descrição passo a passo do trabalho interdisciplinar entre a Geometria e Educação Ambiental, desenvolvido pelos grupos de alunos, desde a fotografia até a maquete física. Já na Figura 13, é possível perceber todos estes momentos reunidos em uma só imagem. O grupo de alunos escolheu reproduzir a Igreja Santa Bárbara de Butiá - Rio Grande do Sul, considerada a padroeira dos mineiros. 


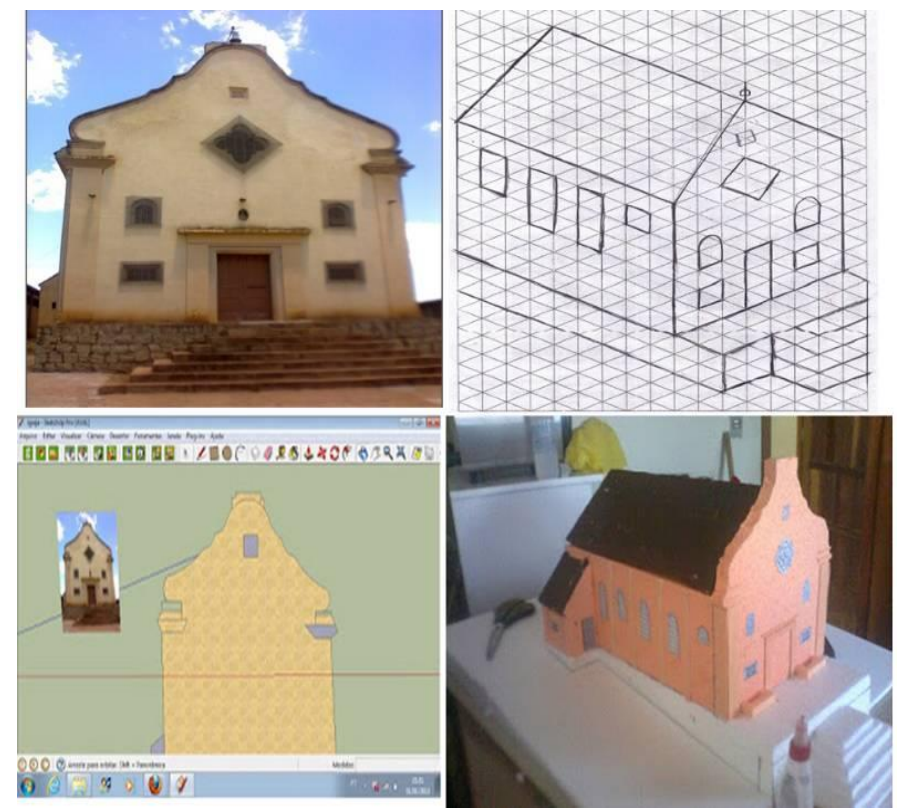

Figura 13: Quatro etapas do trabalho de maquetes.

Fonte: Portfólios virtuais do Eixo.

Para finalizar, no Eixo Geometrias Espaço e Forma apostou-se em um seminário de apresentação das maquetes. A Figura 14 mostra o conjunto de maquetes, de um determinado polo, apresentadas no seminário final.

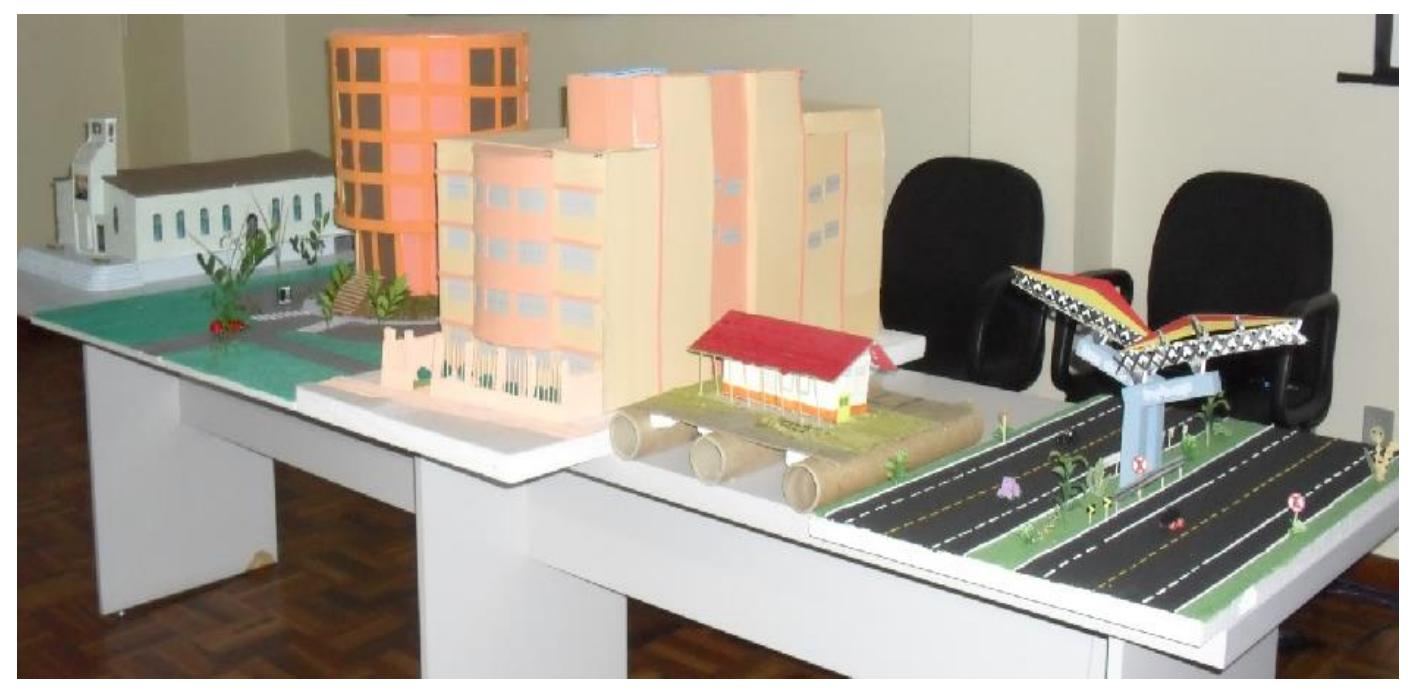

Figura 14: Maquetes físicas de um determinado polo.

Fonte: blog de um polo. 
Logo, cada grupo buscou elementos históricos, formas de medir, escolha de escalas e materiais recicláveis para confeccionar as maquetes físicas e virtuais com o Software livre SketchUp, utilizado e experienciado na quarta atividade. Os relatos e resultados foram apresentados em seminários presenciais nos polos.

\subsection{Análise e discussão dos resultados da estratégia pedagógica Maquetes}

A geometria, segundo Soares (2009), é uma criação humana, ou um conjunto de criações que resultam de maneiras, das quais o ser humano encontra para: planejar o espaço em que vive, intervir nesse espaço, planejar a construção de um objeto etc.

Portanto, considerando as potencialidades da geometria, objetivou-se, neste eixo, a construção de maquetes como estratégia pedagógica, considerada efetivamente como uma atividade interdisciplinar que proporciona inúmeras aprendizagens, visto que os alunos aprenderam conceitos de matemática, geometria, física, educação, educação ambiental, tudo isso de maneira integrada e contextualizada.

O potencial de aprendizagem oportunizada pela experiência de construção de maquetes encontra-se, também, na experiência desenvolvida por Halisk \& Silva (2013) com a $1^{\mathrm{a}}$ série do Ensino Médio, onde os autores citam, com base nos materiais coletados, atividades realizadas e, inclusive através das expressões faciais, o envolvimento dos alunos com o projeto. O mesmo resultado pode ser concluído no caso das atividades do Eixo Geometrias, cujas expressões podiam ser visualizadas nos depoimentos dos portfólios e blogs. Os autores ainda enfatizam que os alunos envolvidos com o projeto apresentaram uma maior facilidade na compreensão dos conteúdos estudados. Isso vai ao encontro do que é citado nos PCNs (1998), quando tratam da importância e da necessidade de metodologias diferenciadas para o ensino do conhecimento científico, assim como, também, no desenvolvimento do espírito critico, criativo e reflexivo do aluno.

Sobre os conteúdos aprendidos em matemática e geometria podemos citar: noções de medidas, escala, figuras planas e espaciais, bem como suas relações, propriedades e operações e volume. Em física, destacam-se conceitos relacionados à óptica geométrica, em educação, as discussões a respeito do planejamento da estratégia das maquetes, por que e como utilizá-la como um futuro professor e, em 
educação ambiental, a política dos 5R (Repensar, Recusar, Reduzir, Reutilizar e Reciclar), política que foi privilegiada na construção da maquete, conforme ressalta determinado aluno: "Os 5R são essenciais na preservação do meio ambiente, assim, para a confecção da maquete faremos o uso de $3 R$, que são reutilizar, reduzir e repensar, pois, através da utilização de materiais descartáveis, estaremos reduzindo o consumo dos mesmos bem como pensaremos na utilidade das embalagens".

Aos poucos, a construção das maquetes agregou outros conceitos e conhecimentos de outras áreas, por exemplo, no momento de escolher e fotografar o prédio/monumento exploraram aspectos relacionados à história do prédio, à cultura da região e à história do seu município. Além disso, desenvolveram a preocupação com a preservação do patrimônio cultural dos municípios bem como o relacionaram ao incentivo ao turismo local. Conforme expressa o aluno: "fiquei surpreso de como nós passamos despercebidos por monumentos existentes na nossa cidade, de todos os trabalhos apresentados, inclusive o feito pelo meu grupo, nenhum eu tinha um breve conhecimento de como e para que foram construídos tais monumentos e prédios".

Já em Física, explorou-se a medida de alturas inacessíveis através da sombra, conforme Tales fez para calcular a altura da Grande Pirâmide de Keops, do Egito. Ele utilizou os seus conhecimentos sobre Semelhança de Triângulos, formados pelas sombras da pirâmide e de uma haste. Nessa perspectiva, os alunos foram alertados que poderiam se valer de tal fenômeno, visto que os mesmos estavam encontrando dificuldade para medir a altura de certos prédios.

Obviamente, muitas dificuldades também foram encontradas pelos alunos no desenvolvimento dessa estratégia, conforme cita o aluno: "Estamos encontrando alguma dificuldade na realização dos detalhes da nossa maquete, por tratar-se de uma igreja, as portas, janelas e alguns ornamentos são de difícil construção, já em contrapartida estou encontrando facilidade na nossa maquete digital pois eu já conhecia o software utilizado".

Embora, o aluno cite sua facilidade ao usar o Software SketchUp, a maioria dos alunos desconhecia esse software. No entanto, além de aprender a trabalharem a sua manipulação, expressaram a importância, nos cursos de licenciatura, do desenvolvimento de diferentes estratégias pedagógicas, possibilitando ao mesmo tempo, conhecer essas ferramentas, trabalhar com softwares no curso e depois utilizálos em suas aulas com a Educação Básica. Conforme outro relato discente: "Em relação 
ao software utilizado, considero muito importante que o professor se familiarize com essas novas tecnologias de ensino, para que o aluno aprenda a interpretar esse novo mundo que emerge com o advento da globalização". Em outro relato, salienta-se a importância da transposição didática entre o que está sendo estudado no Curso e as aulas que desenvolve como professor: "já estou utilizando com meus alunos o Software SketchUp, pois o considero uma ferramenta bastante fácil de manusear". Outro aluno menciona que "é muito interessante essa atividade para aplicarmos com nossos futuros alunos. Acredito que irá facilitar a compreensão dos conceitos geométricos, pois trabalha de forma prática esses conceitos, despertando o interesse e a curiosidade dos alunos".

Essa transposição não é feita somente na escola, também pode ser realizada na família como se evidencia no trecho do depoimento a seguir: "ao chegar em casa, meus filhos de 14 e 8 anos também quiseram construir suas maquetes e já começaram a organizar os materiais". Ainda ressalta que: "Esse eixo valeu a pena por isso, essa atividade se mostrou interessante tanto para crianças do $3^{\circ}$ ano quanto do $8^{\circ}$ ano, podemos explorá-la em diferentes níveis". Ainda, é pertinente citar que a realização desse trabalho foi em equipes, o que foi citado como relevante para os alunos. "Foi muito bom trabalhar dessa forma, cada um contribuiu, aprendemos uns com os outros". A necessidade de trabalhar em equipe é reforçada pelos PCNs, quando faz referência à função da escola, alertando para a necessidade de proporcionar um conjunto de práticas preestabelecidas com propósito de contribuir para que os alunos se apropriem tanto de conteúdos quanto de relações sociais e culturais, de maneira crítica, reflexiva e construtiva com objetivo de criar cidadãos com competências para uma sociedade mais digna (Brasil, 1998).

É importante que os futuros professores tenham uma formação interdisciplinar para que possam desenvolver em suas práticas essas experiências. Nesse sentido, a atividade foi avaliada como positiva, pois a maioria dos alunos percebeu a conexão entre os conceitos trabalhados e a construção da maquete. Como se destaca no trecho a seguir: "Na atividade da construção da maquete, o aluno faz parte de um projeto, onde ele se sentirá motivado para chegar ao resultado final. Ao mesmo tempo, ele estará interagindo com a matéria, ao desenvolver a atividade, pois os alunos são os próprios atores do aprendizado, pois eles participam com uma postura ativa na tomada de decisões e concretização de tarefas". 
A postura interdisciplinar precisa ser vivenciada nos cursos de licenciatura, e essa estratégia pedagógica ultrapassou o planejamento dos professores e incentivou os alunos a buscarem conhecimentos relevantes para a compreensão do que estavam construindo, como é o caso de elementos históricos relacionados aos prédios.

Em relação ao depoimento do aluno: "Pensei que este eixo nunca ia terminar, mas utilizei muito do que aprendi. Foi muito satisfatório, mas muito difícil", percebe-se que uma experiência interdisciplinar exige muito mais do aluno tanto em relação ao tempo como em relação à postura, ele precisa buscar, fazer relações, construir aprendizagens, tendo o professor como mediador, instigador, que, segundo Freire (1996), tem o papel de criar possibilidades e não de transferir conhecimento. Nesse sentido, destaca-se a escrita de outro aluno quando ressalta: "utilizamos quase tudo que estudamos neste eixo para a construção da maquete e se tinha algum conceito que não estava bem definido, depois desta maratona ele se tornou bem mais claro".

Destaca-se como resultado que a estratégia didática cumpriu seu papel na interação entre as disciplinas e ultrapassou os objetivos estabelecidos. Tornou-se uma experiência significativa na opinião dos alunos, pois, além de servir para a construção da própria aprendizagem, foi utilizada nas escolas em suas práticas educativas.

Para finalizar esta discussão, trazemos as palavras de um aluno: "Adorei trabalhar com maquetes e com o software. Nossa maquete foi doada ao Laboratório de Matemática do polo, juntamente com nossas opiniões sobre o uso de maquetes em sala de aula".

\section{Considerações finais}

Consideramos, após o término do eixo, que a atividade das maquetes envolveu os conceitos interdisciplinares pensados, tais como: noções de medidas, escala, figuras planas e espaciais bem como suas relações, propriedades e operações, volume e óptica geométrica. Proporcionou, também, reflexão sobre a metodologia de construção de maquetes e também a política ambiental dos 5R. E de extrema importância foi a capacidade de envolvimento dos alunos e construção de conceitos conforme as falas e as figuras apresentadas nos tópicos resultados e discussões. 
Ainda, a aposta em uma estratégia como essa ganha força por permitir sua utilização em qualquer nível de ensino, proporcionando, assim, que os hoje alunos possam explorar essa estratégia nas suas salas de aula como professores. Outro aspecto que merece destaque neste texto refere-se a um trabalho que não parte da necessidade de pré-requisitos, pois as dificuldades de cada grupo surgem no processo e precisam ser trabalhadas pelo professor e pela pesquisa.

Afinal, a tão criticada formação de professores precisa sim ser repensada, refletida e reorganizada. Sendo assim, ainda fica a questão: como deve ser a formação desse profissional para que o mesmo faça a diferença junto ao seu aluno? A certeza é que a inclusão e intercâmbio de ideias e propostas com outras disciplinas são viáveis e produtivas, tornando o trabalho ainda mais conectado e contextualizado.

No entanto, trabalhar de forma interdisciplinar não é tarefa fácil. Tanto na literatura como na prática, apresenta-se como um desafio, sendo que um dos primeiros passos é estar aberto ao novo, sair da zona de conforto e buscar parcerias no trabalho. Este trabalho demonstra que, como a proposta do eixo é interdisciplinar, os professores precisaram encontrar esses elos e juntos construíram a proposta.

Por fim, um dos grandes desafios da educação na atualidade é permitir o novo, é fazer o diferente, acreditar sim que é possível contribuir para um ensino mais qualitativo, no qual, além de acesso, o aluno permaneça e aprenda mais e melhor, tornando-se um cidadão capaz de tomar decisões em prol de uma sociedade melhor para todos.

\section{Referências Bibliográficas}

Almeida, R. D. de, \& Passini, E. Y. (2002) O espaço geográfico: Ensino e representação. 12. ed. São Paulo: Contexto.

Brasil. (2002). MEC - Resolução CNE/CP 1, art. 11. Institui Diretrizes Curriculares Nacionais para a Formação de Professores da Educação Básica, em nível superior, curso de licenciatura de graduação plena.

Brasil. (2012). Decreto no 5622, de 19 de dezembro de 2005. Art. 10. Regulamenta e estabelece as diretrizes e bases da educação nacional. Disponível em: 
http://www.planalto.gov.br/CCIVIL 03/ Ato20042006/2005/Decreto/D5622.htm

Brasil. (1998). MEC - Parâmetros Curriculares Nacionais - Matemática. Brasília.

Haliski, A. M., \& SILVA, S. de C. R. (2013). Utilização da modelagem para explorar conceitos matemáticos por meio de construção de maquete. Revista eletrônica FAFIT/FACIC, 1(4), 43-56.

Freire, P. (1996). Pedagogia da Autonomia: Saberes Necessários à prática educativa. São Paulo: Paz e Terra.

Lenoir, Y. (2012). Didática e Interdisciplinaridade: Uma complementaridade necessária e incontornável. In Fazenda, I. (Org.). Didática e Interdisciplinaridade. (17a ed.). São Paulo: Papirus.

Lüdke, M., \& André, M. (1986). Pesquisa em Educação: Abordagens Qualitativas. São Paulo: EPU.

Mello, G. N. de. (1998). Diretrizes Nacionais para a Organização do Ensino Médio. Brasília: CNE, Disponível em:

http://portal.mec.gov.br/seb/arquivos/pdf/Par1598.pdf.

Oliveira, L. \& Velasco, A. D. (2007). O ensino da geometria nas escolas de nível médio da rede pública da cidade de Guaratinguetá. Curitiba: Paraná. Disponível em: http://lourivalgomes.com.br/Geometria Artigo 4.pdf

Pinto, A. C., Felcher, C. D. O. \& Otte, J. (2014). O uso de blogs como auxílio no relato de experimentos realizados em encontros presenciais do curso de Licenciatura em Matemática a Distância da UFPel. Disponível em: http://senid.upf.br/2014/wpcontent/uploads/2014/Artigos Resumidos 1920/123762.pdf.

Soares, E. S. (2009). Ensinar Matemática: desafios e possibilidades. Belo Horizonte: Dimensão.

Trindade, D. F. (2013). Interdisciplinaridade: Um novo olhar sobre as ciências. In Fazenda, I. (Org.). O que é interdisciplinaridade? (pp. 71-89).São Paulo: Cortez. 


\section{Apêndice 1: Avaliação on-line 1}

Eixo Geometrias: Espaço e Forma

\section{ATIVIDADE ON-LINE 1}

A Tarefa está discriminada abaixo:

Identificação do aluno:

Nome:

Projeto/Polo:

Prezado Aluno

Na semana 1, foi comentado que no decorrer do Eixo Geometrias pediríamos que cada estudante fotografasse algum prédio histórico, monumento ou ponto turístico da cidade de seu polo. Conforme foi pedido, você deve fotografar, (no mínimo, 3 fotografias) sob diversos pontos de vista (ângulo visual), o local escolhido. Você já deve também anexar estas fotografias no seu portfólio individual, o qual deve ser enviado em arquivo ppt na tarefa disponibilizada no Moodle. Uma das fotos escolhidas deverá se assemelhar a do exemplo da Figura 1.

\section{Diretrizes:}

Esta é uma atividade individual.

Esta tarefa disponibilizada no ambiente Moodle, inicia-se no dia 12/11 e encerrase no dia 25/11/12. Recomendamos que preste atenção nos horários estabelecidos na tarefa. Não deixe para última hora a postagem do arquivo, devido a possíveis problemas técnicos.

Peso da avaliação: 6/100

Os esboços devem ser desenhados sobre as malhas disponibilizadas, a lápis, escaneados, e, após, colados no formato de figuras, atendendo às solicitações das questões.

Trabalho com as fotografias 
1- (15/100) Anexar Fotos (no mínimo, 3), sendo uma sob ponto de vista semelhante à Figura 1.

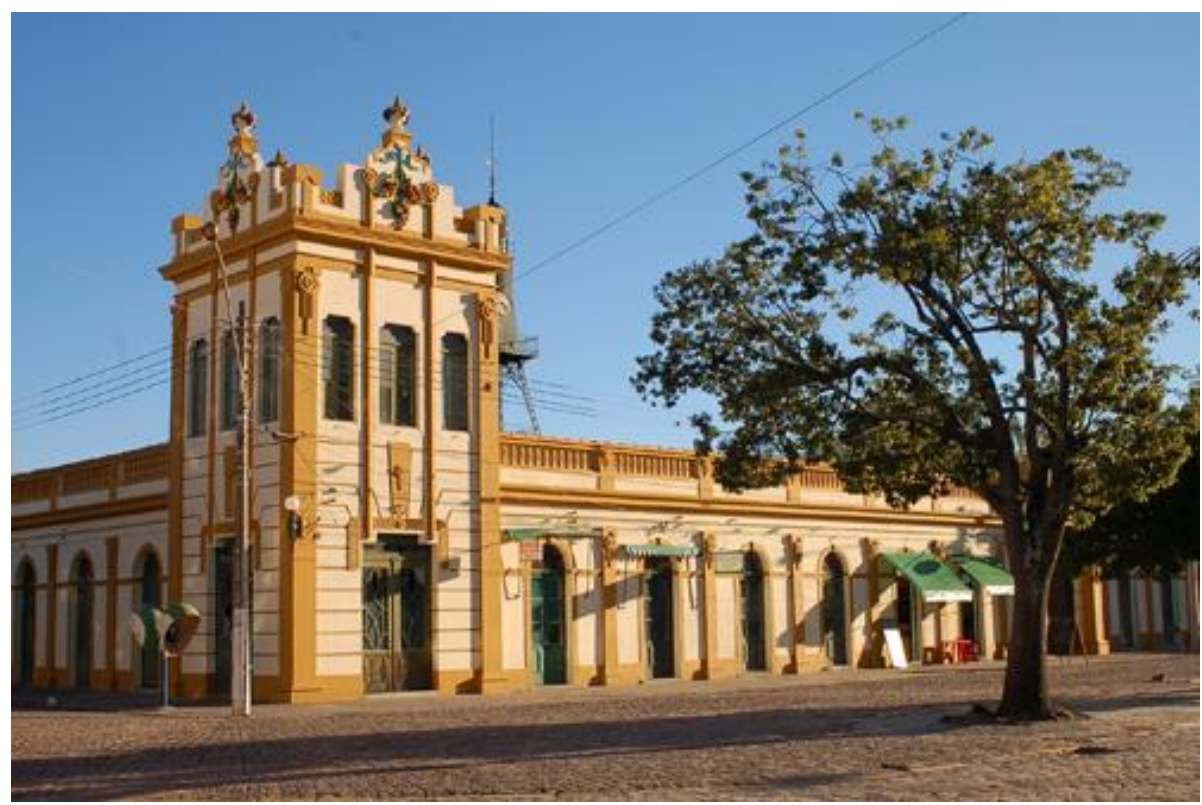

Figura 1: Mercado Público de Pelotas

Fonte: http://www.skyscrapercity.com/showthread.php?t=416588

2- (30/100) Fazer um esboço da fotografia do local escolhido, em perspectiva isométrica, obedecendo às proporções e escalas aproximadas. Utilizar as folhas de papel malha triangular, em anexo.

\section{3- Responda:}

a) (10/100) Uma das fotografias selecionadas deve representar a visualização em perspectiva como o exemplo da Figura 1. De acordo com os conhecimentos adquiridos, por meio da leitura do material didático da semana 2, qual dos tipos de perspectiva se apresenta nesta fotografia?

b) $(15 / 100) \mathrm{Em}$ que a fotografia, em perspectiva, difere da perspectiva desenhada por você na questão 1 ? Explique, redigindo um pequeno texto que contenha o maior número de conceitos existentes no material didático da semana 2 relacionados às perspectivas e ilusão de ótica. 
4- (30/100) Somente a fotografia em perspectiva e a desenhada por você dão uma ideia total dos detalhes do local? É possível desenhar as vistas ortográficas do local de acordo com a fotografia escolhida por você? Com base no texto desta semana, faça um esboço das vistas ortográficas (no mínimo, superior, frontal e lateral direita). Utilize a malha quadriculada. 